\title{
Preparation and Structural Characterization of Vanadium Doped Ni - B Binary Hard Alloys
}

\author{
J. A. Ajao \\ Materials and Electronics Division, Centre for Energy Research and Development, Obafemi Awolowo \\ University, Ile-Ife, Osun State, Nigeria \\ E-mail: jajao@cerd.gov.ng or johnajao2000@yahoo.com
}

\begin{abstract}
The microstructure of a series of binary $\mathrm{Ni}-\mathrm{B}$ alloys containing various amounts of vanadium additions were investigated by Differential Thermal Analysis (DTA), Scanning Electron Microscopy (SEM), Transmission Electron Microscopy (TEM) and Energy Dispersive X-ray Analysis (EDXA). Due to the vanadium addition in the alloys quenched from the liquidus, the formation of the $\mathrm{Ni}_{3} B$ phase was enhanced even when the nominal composition was hypoeutectic. The addition of vanadium led to the formation of $\tau\left(\mathrm{Ni}_{20.4} \mathrm{~V}_{2.6} \mathrm{~B}_{6}\right)$ phase during the present investigation. In addition, the crystallographic orientation relationship of this ternary phase with the nickel matrix was reported. The solid-state eutectoid transformation of the $\mathrm{Ni}_{3} \mathrm{~B}$ phase during cooling was also reported and discussed.
\end{abstract}

Keywords: Alloy, Solidification, Microstructure, Solid-state transformation.

\section{INTRODUCTION}

One of the basic components of the Nickel-based hardfacing alloys are the $\mathrm{Ni}-\mathrm{B}$ hard phases. These hardfacing alloys are specially developed to solve the problems of wear and corrosion in petrochemical, glass, automobile, nuclear and other related industries. They are employed as coatings material deposited by various coating techniques [1-3]. The hard alloys usually consist of nickel as a base metal while chromium, tungsten, molybdenum and vanadium are used as metallic additives and boron, silicon and carbon as non-metallic additives [4]. Addition of chromium promotes the oxidation and corrosion resistance property at elevated temperatures and enhances the hardness of the coating by formation of hard phases. Boron depresses the melting temperature and plays active role in the 
formation of hard phases. The wear resistance property is directly dependent on the relationship between the nickel matrix and hard phases (boride, silicide, carbide) [5, 6]. It also depends on the dimensions and the crystallographic orientation relationship between the phases. Given the various complex hard phases involved in these alloys, the importance of detailed microstructural studies of the alloys cannot be overemphasized. However, only few works report their microstructural features [7, 8]. Hence, this has aroused the interests in the present work to investigate the effect of vanadium additions on the thermal and microstructural properties of the Ni-B hard alloys. The possible crystallographic orientation relationships between the various phases present in the system were also explored and discussed.

\section{MATERIALS AND METHODS}

\subsection{Preparation of the Alloys}

A series of hypo- and hyper-eutectic alloys were prepared in the region of the $\mathrm{Ni}-\mathrm{Ni}_{3} \mathrm{~B}$ eutectic composition. These alloys were prepared from pure nickel, NiB (containing 15wt\%B) and pure vanadium (99.99\% pure). The accurately weighed components of each alloy were arc-melted in an argon atmosphere using a non-consumable tungsten electrode. This operation was repeated several times to ensure the homogenization of the samples. Fig. 1a shows the equilibrium phase diagram for the Ni-B-V system and the position of the alloys investigated.

\subsection{Differential Thermal Analysis (DTA)}

The melting behavior and phase formation were determined by differential thermal analysis (DTA) model 404PC. This apparatus allows the automatic control of thermal programs and automatic analysis of the results. The heating and cooling rate was $5^{0} \mathrm{C} \min ^{-1}$. The samples were also quenched from the liquidus with the cooling rate estimated as $10^{0} \mathrm{Cs}^{-1}$ [9]. The chemical compositions as well as transition temperatures of the alloys are presented in Table 1.

Table 1: Composition (at \%) and transition temperatures $\left({ }^{0} \mathrm{C}\right)$ of the alloys

\begin{tabular}{cccccc}
\hline $\mathbf{N i}$ & $\mathbf{B}$ & $\mathbf{V}$ & \multicolumn{2}{c}{ Transition Temperatures $^{\mathbf{0}} \mathbf{C}$} \\
\hline 82.8 & 16.2 & 1 & 1138 & 954 & 825 \\
81 & 17 & 2 & 1022 & 962 & \\
80 & 17 & 3 & 1076 & 1015 & 940 \\
78 & 17 & 5 & 08 & 1038 & 968 \\
\hline
\end{tabular}




\subsection{Characterization of the Alloys}

Microstructural characterizations of the alloys were carried out using optical and scanning electron microscopes. The samples for SEM observations were slightly etched with an etchant consisting of $5 \mathrm{~g}$ $\mathrm{FeCl}_{3}+10 \mathrm{ml}$ Conc. HCI dissolved in $50 \mathrm{ml} \mathrm{H}_{2} \mathrm{O}$. The crystallographic nature of the phases present in these samples was examined by X-ray diffraction (XRD). Transmission electron microscopy (TEM) and electron diffraction were performed on thin foils of the samples in a JEM-200CX microscope. Thin foils were obtained by electropolish in an electrolyte containing $57 \% \mathrm{H}_{2} \mathrm{SO}_{4}$ at room temperature under $10 \mathrm{~V}$.

\section{RESULTS AND DISCUSSION}

\subsection{Morphology of the Alloys}

\subsubsection{Samples Cooled at Rapid Rate}

A certain number of alloys with varied compositions of vanadium 1 at $\%<\mathrm{V}<5$ at $\%$ were prepared. For alloy containing 1 at $\% \mathrm{~V}$ and quenched from the liquids, the microstructure observed in SEM shows the primary phase of $\mathrm{Ni}_{3} \mathrm{~B}$ (Fig. 1b) surrounded by the lamellar binary eutectic $\mathrm{Ni}(\alpha)-\mathrm{Ni}_{3} \mathrm{~B}$.

It should be noted that for alloy of similar composition but without vanadium addition, the primary phase observed was $\mathrm{Ni}(\alpha)$. Hence, vanadium addition has probably caused the microstructure of the alloy to shift from the hypoeutectic to hypereutectic region during rapid cooling. Detailed observations in TEM of the $\mathrm{Ni}_{3} \mathrm{~B}$ primary phase showed the presence of some precipitates in coherence with the matrix. Fig. 2a shows the transmission electron micrograph on these precipitates while Figs. $2 \mathrm{~b}$ and $\mathrm{c}$ present the diffraction pattern and the key diagram on the precipitates respectively.

From the diffraction pattern obtained on the precipitates and the energy dispersive X-ray analysis (EDXA) performed on them, a ternary $\tau\left(\mathrm{Ni}_{20.4} \mathrm{~V}_{2.6} \mathrm{~B}_{6}\right)$ phase could be proposed. The lattice parameter

of this ternary phase varies between $10.47 \AA$ and $10.49 \AA$ [10]. Similar ternary phase has been reported in Ni-B-Si [11] and Ni-B-Ti $[12,13]$ systems.

For alloys containing 3 to 5 at $\% \mathrm{~V}$ and quenched from the liquidus, SEM observations only revealed the binary eutectic structure between $\mathrm{Ni}(\alpha)$ and $\mathrm{Ni}_{3} \mathrm{~B}$. Unlike boron, vanadium is more soluble in nickel. Hence the domain of existence of the ternary phase $\tau$ (Fig. 1a) is much more reduced. Furthermore, Fig. 3 shows the TEM observations on the binary eutectic $\mathrm{Ni}(\alpha)-\mathrm{Ni}_{3} \mathrm{~B}$ obtained in alloys containing $3-5$ at $\% \mathrm{~V}$ quenched from the liquidus. The binary eutectic is lamellar with the lamellae of $\mathrm{Ni}_{3} \mathrm{~B}(1500 \AA)$ about twice the size of the $\mathrm{Ni}(\alpha)$ lamellae $(800 \AA)$ as shown in the transmission electron micrograph of Fig. 3a. 

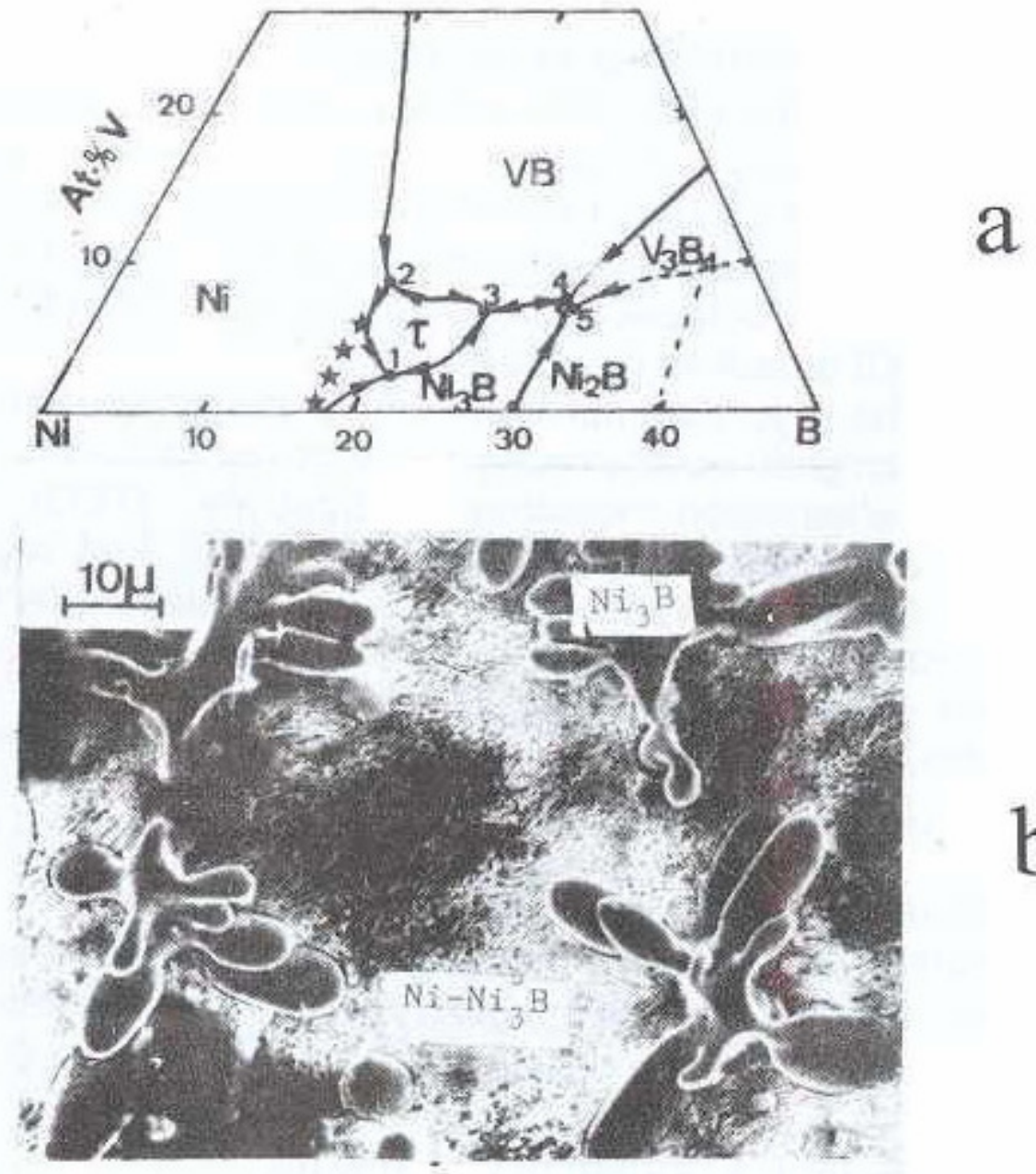

b

Fig. 1: (a) Equilibrium phase diagram for the Ni-B-V system and the position of the alloys investigated (b) Scanning electron micrograph of alloy containing 1 at $\% \mathrm{~V}$ showing the primary phase of $\mathrm{Ni}_{3} \mathrm{~B}$ surrounded by the $\mathrm{Ni}(\alpha)-\mathrm{Ni}_{3} \mathrm{~B}$ eutectic 

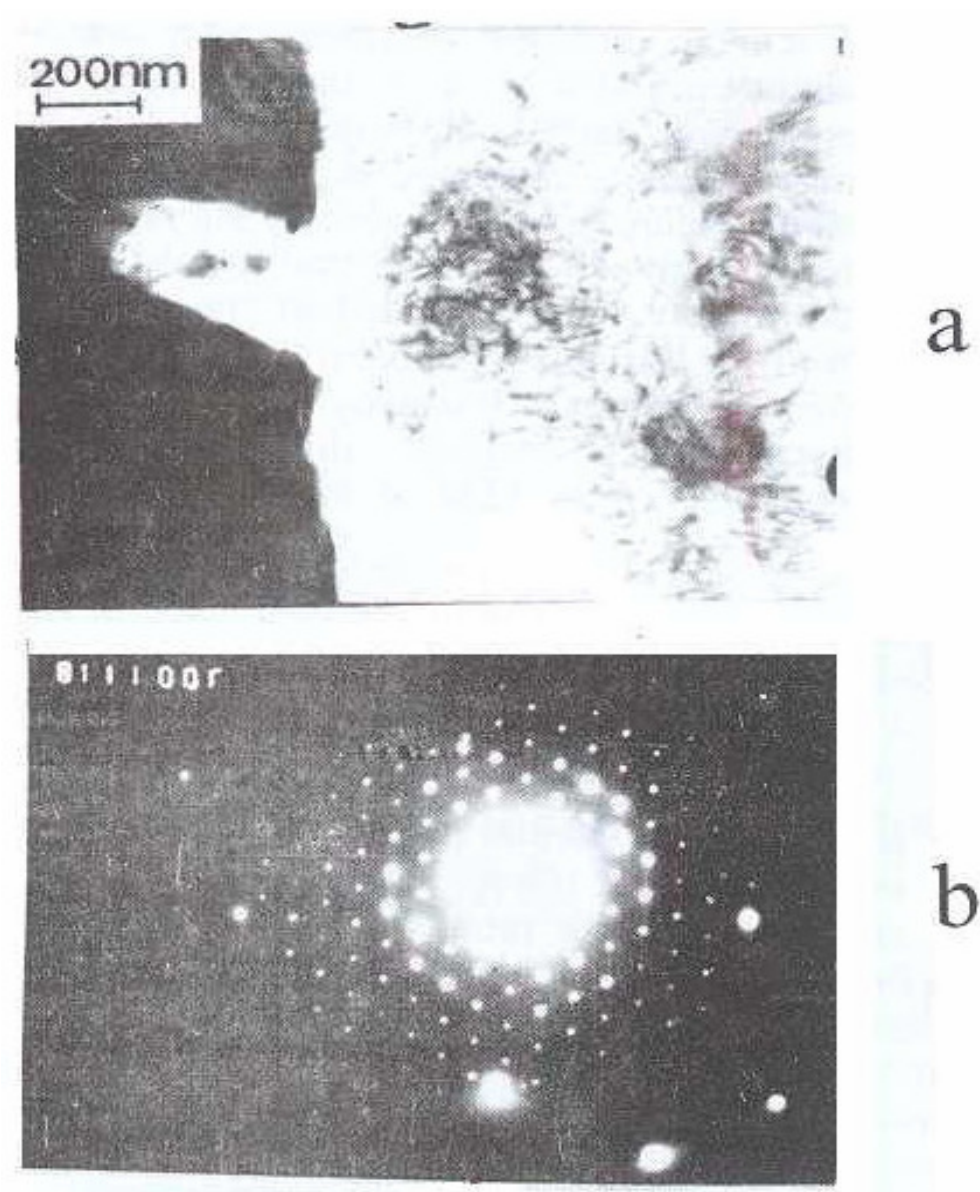

b

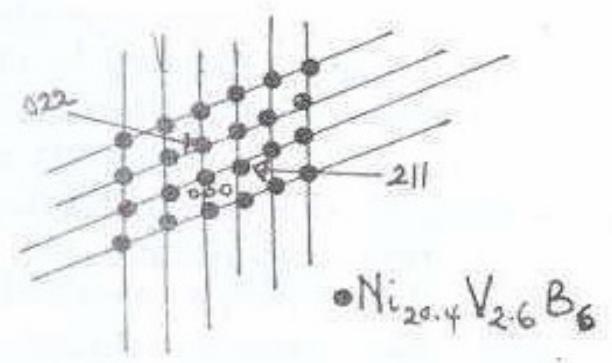

C

Fig. 2: (a) TEM on the $\tau\left(\mathrm{Ni}_{20.4} \mathrm{~V}_{2.6} \mathrm{~B}_{6}\right)$ ternary phase (b and c) Diffraction pattern and the key diagram on the $\tau$ precipitates 

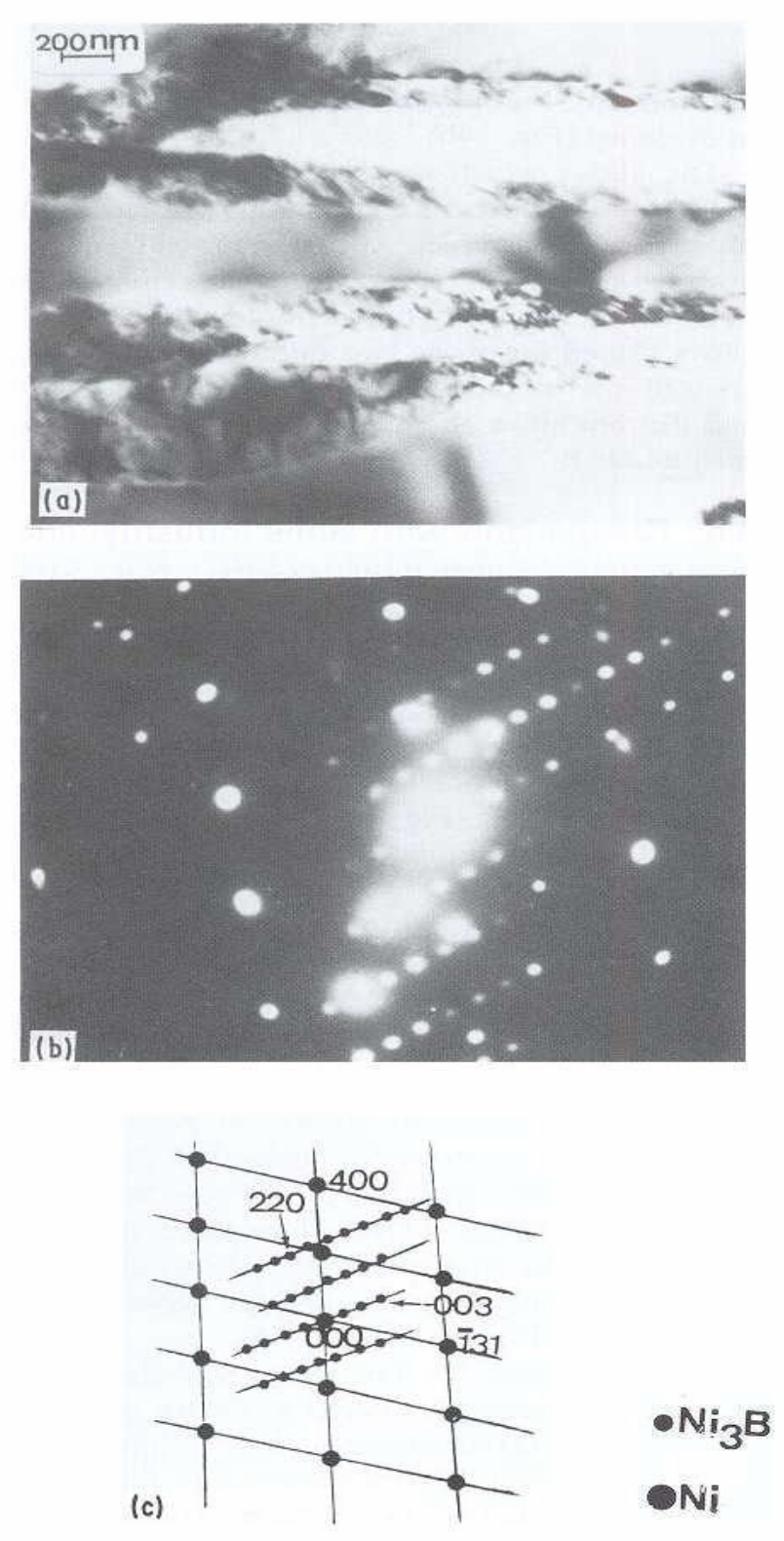

Fig. 3: (a) TEM observations on $\mathrm{Ni}(\alpha)-\mathrm{Ni}_{3} \mathrm{~B}$ eutectic quenched from the liquidus $(\mathrm{b}$ and $\mathrm{c}$ ) Diffraction pattern and the key diagram on the $\mathrm{Ni}(\alpha)-\mathrm{Ni}_{3} \mathrm{~B}$ eutectic.

\subsubsection{Differential Thermal Analysis (DTA) Samples}

For alloys containing 2 at $\% \mathrm{~V}$, the crystallization of the alloys started with the primary formation of the $\mathrm{Ni}(\alpha)$ phase at $1022^{\circ} \mathrm{C}$ followed by a solid state precipitation of the $\mathrm{Ni}_{3} \mathrm{~B}$ phase at $962^{0} \mathrm{C}$ (Fig. $4 \mathrm{~b}$ ). This appears as slabs in the figure. It would be recalled that for similar alloys quenched from the liquidus, the primary phase formed was $\mathrm{Ni}_{3} \mathrm{~B}$ followed by the binary eutectic $\mathrm{Ni}(\alpha)-\mathrm{Ni}_{3} \mathrm{~B}$. 

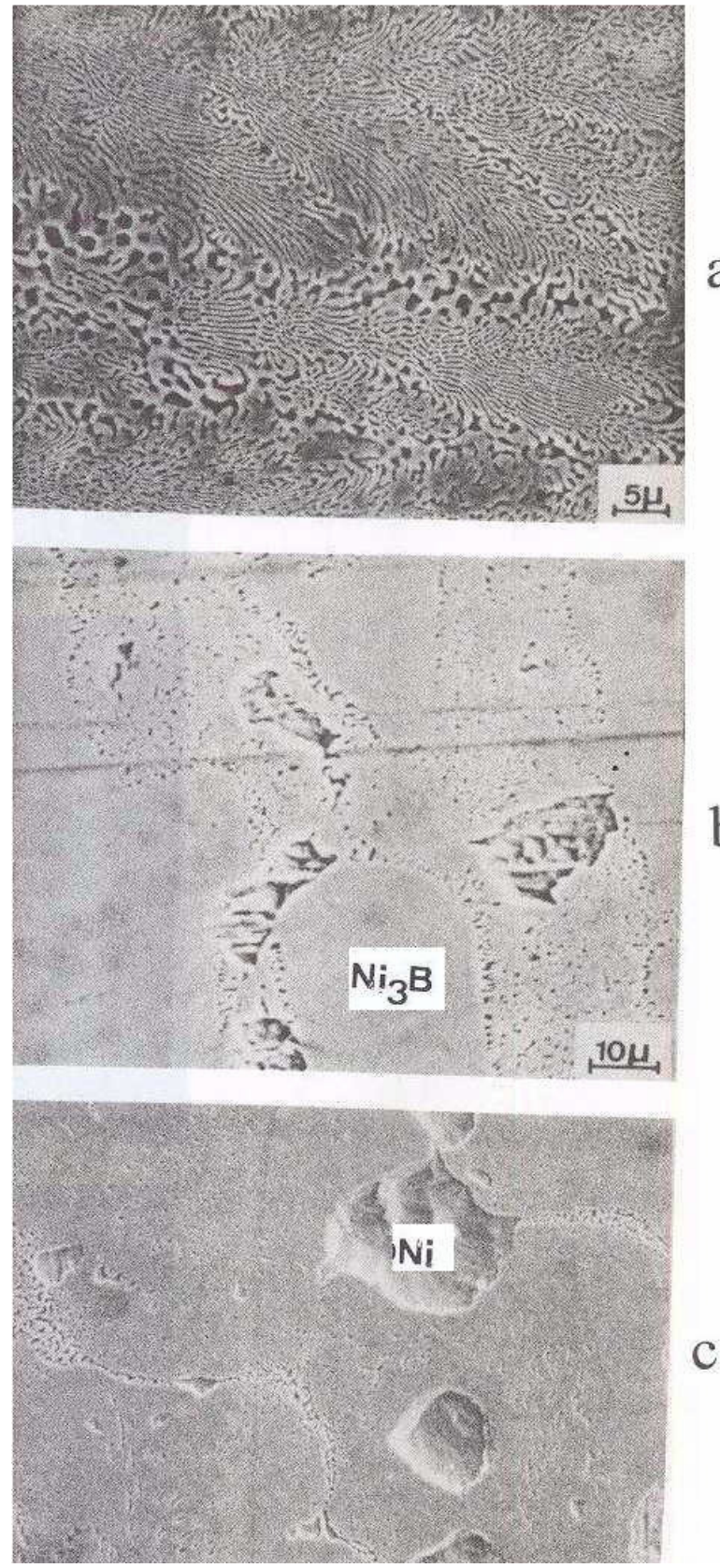

Fig. 4: (a) Solid-state precipitation of the $\mathrm{Ni}_{3} \mathrm{~B}$ phase in alloy containing 2 at $\% \mathrm{~V}$ during cooling in DTA (b) SEM observations on alloys containing $3-5$ at \% V slowly cooled in DTA (c) Haloes of Ni $(\alpha)$ in alloys containing 5 at $\% \mathrm{~V}$ with interdendritic precipitations

In the same vein, for alloys containing 5 at $\% \mathrm{~V}$, three transitions temperatures were observed in DTA experiments. This alloys started its crystallization by the formation of the primary phase of $\mathrm{Ni}(\alpha)$ at $1108^{\circ} \mathrm{C}$ followed by the crystallization of the binary eutectic $\mathrm{Ni}(\alpha)-\mathrm{Ni}_{3} \mathrm{~B}$ at $1038^{\circ} \mathrm{C}$ as shown in Fig. 4a. As the temperature continued to decrease, this $\mathrm{Ni}_{3} \mathrm{~B}$ phase underwent a solid-state transformation at 
$968^{0} \mathrm{C}$ as evidenced in the interdendritic grooves in the micrograph in Fig. 4c. Similar observations have been reported during slow cooling of $\mathrm{Ni}-\mathrm{B}$ alloys doped with titanium [13]. In fact, at $968^{0} \mathrm{C}$, the non-stoichiometric $\mathrm{Ni}_{3} \mathrm{~B}$ was saturated with the atoms of nickel and vanadium at the same time. The rejection of these atoms of nickel and vanadium to the interface gave rise to the solid-state transformation (eutectoid-like structure) as follows:

$$
\mathrm{Ni}_{3} \mathrm{~B}(\mathrm{Ni}, \mathrm{V}) \rightarrow \mathrm{Ni}_{3} \mathrm{~B}+\mathrm{Ni}(\mathrm{V}) \quad\left[\Delta \mathrm{H}=20 \mathrm{~kJ} \mathrm{~kg}^{-1}\right]
$$

The relation between the thermal effect due to the change of state and the surface area of the peak in DTA experiment is given by

$$
\mathbf{m} \Delta \mathbf{H}=\mathbf{k S}
$$

where

$$
\begin{aligned}
\mathrm{m} & =\text { mass of the melt } \\
\Delta \mathrm{H} & =\text { enthalpy of transformation } \\
\mathrm{S} & =\text { surface area of the peak in DTA } \\
\mathrm{k} & =\text { heat transfer coefficient }
\end{aligned}
$$

For the alloy undergoing solid-state transformation (with $\mathrm{m}=0.002 \mathrm{~kg}$ ), the enthalpy of transformation has been estimated as $20 \times 10^{3} \mathrm{~J}_{\mathrm{kg}}{ }^{-1}$ [9]. From the DTA trace, the surface area of the peak during transition at $954^{\circ} \mathrm{C}$ was calculated as $55 \times 10^{-6}$. Hence, from the above relation and data, the heat transfer coefficient $(\mathrm{k})$ between the crucible and the melt has been estimated as $8 \times 10^{5} \mathrm{~W} \mathrm{~m}^{2} \mathrm{~K}^{-1}$. This is in good agreement with the value obtained by Casanova et al. [15]. It is also important to report that the hardness measurements carried out on these samples showed a higher value for alloys with vanadium additions due probably to the formation of some pockets of VB hard phases which might be present in the alloys.

\subsection{Crystallographic Orientation Relationship between $\mathrm{Ni}(\alpha)$ and $\mathrm{Ni}_{3} \mathrm{~B}$}

The superposed diffraction pattern of the two phases is shown in Fig. 3b while the key diagram is presented in Fig. 3c. From the superposed electron diffraction pattern of the two phases, the following relative crystallographic orientation relationship between the two phases could be deduced:

$$
\begin{aligned}
& (200)_{\mathrm{Ni}(\alpha)} / /(221)_{\mathrm{Ni3B}} \\
& {[013]_{\mathrm{Ni}(\alpha)} / /[110]_{\mathrm{Ni3B}}}
\end{aligned}
$$

This orientation relationship is quite different from those obtained from pure $\mathrm{Ni}(\alpha)-\mathrm{Ni}_{3} \mathrm{~B}$ eutectic quenched from the liquidus [9] showing the pronounced influence of vanadium addition. However, this mutual crystallographic orientation between the two phases is comparable to the orientation relationship observed between them in meltspun Ni-B alloys [14]. From the above crystallographic orientation relationship, the lattice mismatch could be estimated as $33 \%$ for the $[013]_{\mathrm{Ni}(\alpha)} / /[110]_{\mathrm{Ni} 3 \mathrm{~B}}$ direction. This value is far greater than $10 \%$ which could have made the planes special. These 
observations show the apparent effect of cooling conditions on the orientation and the growth of the interface.

\section{CONCLUSION}

A series of Ni-B alloys containing various amount of vanadium additions were studied using various characterization techniques. Precipitates of a ternary phase identified as the $\tau$ - phase and coherent with the matrix were observed in the alloys during quench from the liquidus. The mutual crystallographic orientation relationship of this ternary phase with the matrix was also reported. In addition, solid-state transformation of the $\mathrm{Ni}_{3} \mathrm{~B}$ phase during slow cooling was reported and an explanation attempted.

\section{ACKNOWLEDGEMENTS}

The author is thankful to Dr. D. A. Pelemo for helpful discussions on electron microscopy. The Centre for Energy Research and Development, Obafemi Awolowo University, Ile-Ife, Nigeria is appreciated for granting the author leave of absence during the preparation of this work.

\section{REFERENCES}

[1] Fernandez, E., Cadenas, M., Gonzalez, R., Navas, C., Fernandez, R. and J. de Damborenea, 2005, "Wear behaviour of laser clad NiCrBSi coating", Wear 259: 870-875.

[2] Gonzalez, R., Garcia, M. A., Penuelas, I., Cadenas, Rocio, Fernandez, Ma. Del., Hernandez Battez, A., and Felgueroso, D., 2007, "Microstructural study of NiCrBSi coatings obtained by different processes", Wear 263: 619-624.

[3] Knotek, O., Lohage, P. and Reimann, H., 1983, "Nickel-based Wear-resistant Coatings by Vacuum Melting", Thin Solid Films 108:449-458.

[4] Knotek, O., Reimann, H. and Lohage, P., 1981, "Reactions between Ni-Cr-B-Si matrixes and carbide additives in coating during fusion treatment", Thin Solid Films 83:361 - 367.

[5] Lebaili, S., Durand-Charre, M. and Hamar-Thibault, S., 1988, "The Metallurgical Structure of as solidified Ni-Cr-B-Si-C Hardfacing Alloys”, J. Mat. Sci. 23:3603-3611.

[6] Chin-you Hsu, Jien-Wei Yeh, Swe-Kai Chen and Tao-Tsung Shun., 2004, "Wear Resistance and High-Temperature Compression Strength of FCC CuCoNiCrAl ${ }_{0.5} \mathrm{Fe}$ Alloy with Boron Addition”, Metallurgical and Materials Transactions A Vol 35A: 1465 - 1470.

[7] Lebaili, S, Ajao, J. and Hamar-Thibault, S., 1992, "Preparation and Characterization of meltspun nickel-based alloys containing heavy metals", J. Alloys Compd. 188: 87-93.

[8] Li, Q., Zhang, D., Lei, T., Chen, C. and Chen, W., 2001, "Comparison of laser-clad and furnacemelted Ni-based alloy microstructures”, Surf. Coat. Technol. 137:122-135. 
[9] Ajao, J. and Hamar-Thibault, S., 1988, "Influence of Additions on the Solidification behavior of Ni-B alloys - crystallography of Ni-Bi3B eutectic", J. Mater. Sci. 23: $1112-1125$.

[10] Stadelmaier, H. H. and Balance, G. B., 1967, “The Ni-V-B Ternary System”, Metall. 21, 691-695.

[11] Knotek, O. and Lugscheider, E., 1974, "On the Structure of Ni-Cr-B-Si Hardfacing Alloys and their Bonding Reactions", J. Vacuum Sci. Tech. 11:798 - 801.

[12] Finch, C. B., Becher, P. F., Ferber, M. K. Tennery, V.J. and Yust, C. S., 1982, "Growth and Properties of $\mathrm{Ni}_{20.3} \mathrm{Ti}_{2.7} \mathrm{~B}_{6}$ ( $\tau$ - phase) Crystals", J. Cryst. Growth 58: $647-649$.

[13] Ajao, J. A., 2009, "Phase transitions in some nickel-rich nickel-boron-titanium hard alloys", $J$. Alloys Compds. DOI:10.1016/j.jallcom.2009.12.091.

[14] Ajao, J. and Hamar-Thibault, S., 1989, "Structure Observations by High Resolution Electron Microscopy of Ni-B Meltspun Alloys", J. Mater. Sci. 24:3647-3659.

[15] Casanova, P., Joud, J.C. Senillou, C. and Yavari, A. R., 1984, "Elaboration des Rubans larges de Verres Metalliques", Mem. Sci. Rev. Met. 81:553-559. 